\title{
Los escritos políticos de Immanuel Kant
}

- Mario Estuardo López Barrientos

\section{Presentación}

El objelivo principal de este trabajo es conocer la rellexión política de Immanuel Kant. A Kant lo solemos conocer por su crítica a la melalísica y la consiguiente cimentación de los límiles y posibilidades de conocimiento cientilico; así como por su imperalivo callegórico que sugiere el deher ser racional en calda ser humano, en el ejercicio de su libertad. Son limosals, y de complicada lectura, sus tres crílicass: Crítica a la Razón Pura. Crítica a la Rasion Práctica y Crítica del Juicion. También son conocidas sus obras en filosolía de la religión y lilosofía del derecho. Sin embargo, son muy poco conocidos acpuellos escritos de Kant que versaron sobre la polílica y la historia, escritos que podríamos calilicar de 'menores'. en parte porgue se trata de temas aislados y no de obras sistemálicas.

Para la selección de los escritos propiamente polílicos, me he ceñido a la edición inglesa de Hans Reiss titulada Kamt's Political Writings, por ser la única en esta universidad que realiza este trabajo de selección. Sobre los escritos polílicos de Kant no haly mucha información, ni en Internet ni en libros en español. Tan sólo haly pequeños ensayos y estudios preliminares que se encuentran en sus obras polílicals ediladas en español, sobre lodo los de Rodrígue\% Aramayo que ofrecen interesantes y sugerentes puntos de análisis.

Me he precoupado en dar una noción acerca de la época, con la idea de enmarcar el pensamiento político de Kant. También presento la vida y obra del autor, tratando de desglosar así el conjunto de su producción intelectual y el meollo de su pensamiento. Además, ofrezco algunos datos relevantes que nos ayudan a entender esta veta política en Kant: las posibles influencias, las problemáticas que trata, y

Los escritos políticos de Immanuel Kant 
el legado que deja a la traddición libosólical. Luego presento su pensamiento polílico. Acjuí pensé en un inicio hacer recensiones a cada uno de sus escritos, con elilin de incentivar su leclura; sin embargo, me parecía un trabajo, auncjue de sínlesis. poco crealivo y en algunas veces repelitivo, puesto gue hay lemálicals (jue van y vienen a lo largo de lales escritos. Por esto, prelerí destacar las grandes temálticass de su pensamiento polílico. Iil único libro al gue no luve aceeso en español, entre los seleccionados, lue Melafisica de las Costumbres, el cual excluimos del presente trabajo.

\section{Contexto: La Edad Moderna}

No nos interesal acpuí presentar un amplio estudio de la Eedad Moderna, sino ubicar a Immanuel Kant dentro de su épocia. En este sentido dejamos de lado el debale gue existe entre las diferentes historiogralías sobre los límites de la Modermidad, a la par gue también nos alejamos del detalle de hechos y acontecimientos gue sucedieron en las emergentes naciones, y nos concentramos, en cambio, en alpuellos elementos generales gue caracterizan dicha modernidadl:

\subsection{Dimensión religiosa}

İn el cimbito de las (reencias. el hecho más elocuente del inicio de la Modernidad es la quichra de la unidad cristiana en Iiuropa Central y Occidental, precedido del agyilado caldo de cultivo de las herejías y las contestaciones críticals a la Iglesia romana en la haja I:dad Media y gue culmina en la Relorma protestante y el inicio de un largo ciclo de las guerrals de religión descle principios del siglo XVI. Asimismo, la secularización del saber, la consolidación de la ciencia y el avance del libre pensamiento, hasados en el pilar de la razón, generarín aclitudes crílicas hacia las religiones reveladas.

\subsection{Dimensión cultural}

El nuevo marco cultural perfilado en el renacimiento y el humanismo generarín un escenario en el (lesarrollo del saber donde el hombre ocuparía un lugar central, cuya proyección alcanzaría su más elocuente forma de expresión en el espírilu de la Ilustración en el siglo XVIII y la configuración de Europa como paradigma de la modernidad.

lislos cambios en la almóslera cultural y su manilestación en los avances lecnológicos revolucionarán los hábilos materiales de las sociedades curopeass y su visión y relación con el entorno a escala planelaria. Los nuevos inventos, en la navegación y en el campo militar, por cilar dos cjemplos, facilitarán los descuhrimientos geográlicos y la apertura de nuevas rulas marinas hacia los mercados de Extremo Oriente y hacia el Nuevo Mundo. 


\subsection{Dimensión económica}

Desde una perspectival socionecomomica, la lenta pero progresiva implantación de lormas protocapitalistas, vinculadas al desarrollo del mundo urbano desde los sigglos XII y XIII, y el creciente peso de la actividad mercantil y artesanal en unas sociedades lodavía agrarias, irán deliniendo los rasgos de la sociedad capilatlista. Ayuellas translormaciones económicas transcurrirán paralelas al proceso de expansión de la aclividad económica de los europeos en otros mercades mundiales. hien ejerciendo unas relaciones de explotación sobre sus dependencials coloniales o bien en un plano más igualitario, en primera instancia. en otras áreas del globo, como expresión de la emergencia mundial de las potenciats europeals.

\subsection{Dimensión social}

Las translormaciones económicas transcurrieron parcjas e indisociables a cierlos cambios en la cestructura sorcial del Antiguo Régimen. Inntréstos, el protagonismo de nuevos grupos sociales muy dinámicos en su comportamiento, tradicionalmente asimilados al complejo concepto de burguesia. los cuales recurrirán a distinlass estrallegias lanto de corte relormista como revolucionario para su promoción social y política y la salvaguardia de sus intereses económicos. Movimientos (que no convienen simplificar y superponer a obros lenómenos sociales que atañen a otros sectores de la población, lanto agraria como urbana, de carácter más revolucionario, como se pueden observar en el siglo XVII en el marco de la revolucion ingleser; o las estralegials de los grupos tradicionales de poder para lirenar o neutralizar esos movimientos mediante la cooptación de esa hurguesía emergente o mediante el recurso a práclicals represivals. De cualcpuier modo. estas pautas de translormación social conducirían con mayor o menor eceridad y con las peculiaridades propias de carda sociedad a la antesala del ciclo de revoluciones hurguesals que se iniciaría deste linales del siglo XVIII y que supondría, en lérminos generales, el desmantelamiento del Antiguo Régimıen.

\subsection{Dimensión política}

Desde la perspectiva política, el lenómeno más relevante es la conliguración del Estado moderno, las primeras monarguiass nacionales, las cuales se irán abriendo paso a medida que se diluya la idea medieval de imperio cristiano a lo largo de las luchas de religión del siglo XVI. El nacimiento del Estado moderno concrelará la expresión de nuevas lormass en la organización del poder, como la concentración del mismo en el monarcal y la concepción patrimonialista del Estado, la generación de una hurocracia y el crecimiento de los instrumentos de coacción, mediante el incremento del poder militar, o la aparición y consolidación de la diplomacia, conjuntamente al desarrollo de una teoría política ad hoc. Fórmulas que culminarían en el Estado absolutista del siglo XVII o en los despotismos ilustrados del siglo XVIII, pero que no pueden ocultar la complejidad

Los escrilos poríticos de Immanuel Kant 
de la realidad polítical europea y el desarrollo de modelos de gobierno alternativos, como las lormas parlamentarias que se lueron implantando desde el siglo XVII é Inglaterra, y que vaticinan en la práctica y en sus teorizaciones el posterior desarrollo del liberalismo.

\subsection{Dimensión internacional}

En su dimensión internacional, la emergencia y la conliguración de la Europa moderna perlilará una nueva visión y una inćdita actitud hacia el mundo, y en esa perspectiva la modernidad implica el inicio de los encuentros, y lambién desencuentros, con otras civilizaciones a lo largo del globo.

Los descubrimientos geográlicos y las nuevas posibilidades habilitadas por las innovaciones técnicas translormarán radicalmente la visión que del mundo tendrían los europeos. Un cambio de actitud que conjuntamente con las transtormaciones sociocconómicas, culturales y políticas llevará a los curopeos a expresar su extroversión hacia ultramar y concretar en el plano internacional la emergencial de Europa. En ese proceso, los curopeos entrarán en contacto con otros mundos y con otras civilizaciones, no siempre con un ánimo dialogante, sino con la pretensión de imponer sus formas de civilización, o dicho de otro modo, con la intención de crear otras Europas, siempre que encontraran las circunstancias adecuadas para hacerlo. Es cierto que en el caso de América, el Nuevo Mundo se convirtió en el punto de destino de las utopías del viejo continente, pero en el plano general de la política curopea hacia estas áreas, como más adelante ocurriría con la expansión curopea por otros continentes, se plantearía en términos de desigualdad en favor de las metrópolis curopeas.

Por último, la emergencia y la progresiva hegemonía mundial curopea acabaría influyendo en el desarrollo de las relaciones internacionales, en la misma proporción que su expansión por el globo, aún lejos a finales del siglo XVIII de lo que sería la culminación de las prácticas imperialistas y de la hegemonía europea en vísperas de la I Guerra Mundial. La crisis del universalismo imperial y pontilicio (la cristiandad medieval) entre los siglos XIV y XVI dejará paso a una nueva realidad internacional europea definida por el protagonismo de los estados modernos, la pluralidad de los estados soheranos, y la configuración del 'sistema de estados europeos', cuya acta de nacimiento bien puede datarse en la Paz de Westfalia de 1648. Los Estados y, concretamente, las grandes monarquías curopeas de los siglos XVII y XVIII, serán el elemento predominante en las relaciones internacionales de la edad moderna y al designio de ćstos quedará relegadas la suerte de las posesiones europeas de ultramar y las posibilidades de penetración en otros mercados extraeuropeos. 
En resumen, podemos decir que la modernidad se caraclerizó por: (a) en lo religioso, crílica severa a la Iglesia Calólical y a la religión en general, seculariración del saber y emergencia del librepensamiento; (b) en lo cultural, el papel preponderante del saber ${ }^{2}$, bassado en la razón, en la idea de progreso, y en la responsabilidad humana de dominar el mundo; (c) en lo económico, inicio del capitalismo y expansión económica de Luropa en otros mercados mundiales; (d) en lo social, ascenso de la hurguesía; (e) en lo polírico, conliguración del Estado moderno, absolutismos y parlamentarismo, burocracia y crecimiento de mecalnismos de coerción; y (l) en lo internacional, expansión colonial, relaciones internacionales entre bistados y eurocentrismo.

\section{Vida y obra de Immanuel Kant'}

Immanuel Kant nace un 22 de abril de 1724 en Kïnigsherg, capital del ducado de Prusia, cuarto de los once hijos del macstro gualrnicionero Johann (ieorg Kant y de su mujer Anna Regina Reuter. Su madre. de religiosidad piedista, se encargaría de la educación del joven Manolito (Mamele/e'n). inlluyendo enormemente en su luturo carácier moral.

Entre 17.32 y 1740 asiste al Collegium liridericianum, dirigido por F. Albert Schuly. (1692-176.3). un piedista seguidor de la libosolía dogmálica de Wollt. La instrucción que alli recibio, plagada de plegarias, oraciones y príclicals piadosals. cerminó calusando una gran aversión por la práctica religiosa. De hecho, en su edad adula. Kant no assistió nuncia a la Iglesia. En 17.38 muere su madre. En 1740, Kant ingresa en la universidad de Königsherg, el mismo año que léderico el (irande pasal a ocupall el trono de Prusia. Inntre sus estudios estín teología. lílosolía, maltemálicals y ciencials nalurales. Su profesor Martin Knuten le inicia en la leclura de Newton y otros autores ingleses. Kant ya no reside en la calsa palerna y se gana la vida dando clases particulares. In 1746 muere su padre y Kant deja la universidad antes de graduarse. I

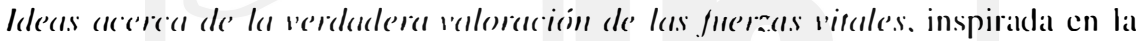
lísica de lecibniz y con el cye inicia el denominado perioden pre-críticos. que durará hasta 1770). Trabaja como preceptor privado de familias pudientes, en los alrededores de Känigsherg. Issce seraí el desplazamiento más largo que Kant realizará en su vida.

I latín Sobre el firegere y asume el puesto de prolesor auxiliar (Privenderenertr) eon un

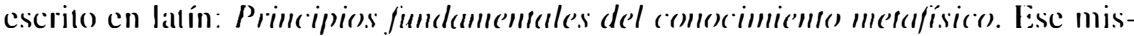

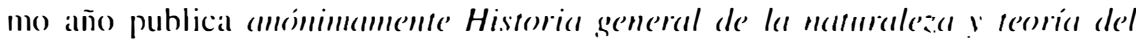
ciclo, en la cue propone una cosmogonía mecanicista, de inspiración newloniana. anticipando la lesis de Kant-I aplace sobre el origen del universo. Se mantendrá en este puesto los quince años siguientes, impartiendo classes de lísica, matemá-

\section{1}

Los escritos políticos de Immanuel Kant 
licas, geogralía, cosmología y teología. Kant lec a Leibniz y Hume. Este último autor le despertará de su "sueño dogmático". En 1756, Kant presenta su tercer ralado en latín, Sobre la momadología física, para poder presentarse a la cátedra de lógica y metalísica, aunque no liene éxito.

In 1762 escribe La falsa sutileza de las cuatro figuras del silogismo. Para esta lecha, Kant continúa dando clases, a las que asiste de oyente J. G. Herder. También escribe El único) argumento posible para demostrar la existencia de Dios. Un año después obliene el segundo premio de la Academia de las Ciencias de Berlín con la obra Esfudios sobre la evidencia de los principios de la teología y la moral maturales. Escribe Ensay'o para introducir el concepto de magnitudes ne.geririvas en filosofica. En 1764 queda disponible la cátedra de poesía en Berlín, y Kant la rechava. Escribe Observaciones sobre el semtimiento de lo bello y lo sublime, y un breve tralado: Ensayeo sol)re las enfermedades de la cabeza. Un año después Kant loma el cargo de vicehihliotecario del Palacio Real. Cuando lee la obra de Swedenhorg (Córlestia Arcana), un teósoló, ciéntilico y místico sueco que prelendía describir sus incansables viajes por el cielo y el inlierno, Kant arremete contra él escribiendo una obra hurlona litulada Suerinos de all visiomario explicados por los suenoss de la metafisica (1766), donde rechaza delinilivamente el lipo de melalísicia, lan alejado de la experiencia y se inclina ya por una concepción de la lïlosolía cemo la ciencia de los límiles de la razón humana, y no como un sistema de saber; la lilosolía, más (jue conocimiento, es para él crílica (lel mismo.

In 1769, Kant rechaya la cíledra de prolesor ordinario en Iirlangen. I:I pensaldor se halla ya luertemente influenciado por la lilossolía de Rousscia. In año después es nombrado caledrálico de lógica y metalísica en la Iniversidald de Königsherg. Presenta una disertación en lalín: Disertacion sol)re la forma y los mrincipios del mumelo sensible e inteligible. en el que intenta aclarar porcué la mclall ísical se hallaba en un callejón sin sillida. En esta obra Kant establece una diferencia entre conocimiento sensible y conocimiento inteligible, de modo que el conocimiento no yueda limilado meramente a la experiencia, debiendo reconocer. por lo mismo, un conocimiento metalísico que dehe justilicarse. Aquí comienza la consitrucción de la que será llamada filossofía trascendental, edilicalda sobre la línea de un sujeso gue pone sus condiciones subjelivas a la posibili-

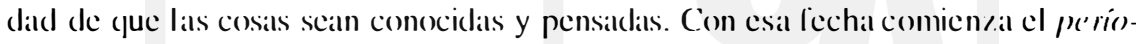

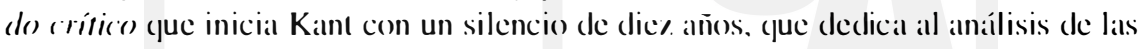
objeciones gue se le lomularon a su propuesta inicial de señalar las característicals del conocimiento sensible y del intelectual. Lal 'gran lus' (jue Kant dijo ver no es oral cosal (jue la noción de sujeto trascendental, a saber. aleuel gue pone a la malleria del conocimiento la manera o loma de conocer o representar las cosils.

I in 1772 cesal su trabajo como hibliotecario del Palacio Real y en 1780 ingresa en el senade de la Iniversidad de Königsherg. Iin 1781 publical su gran obra:

\section{2}

Realidad 84, 2001 
('rítica de la razón pura, tras un período de doce años de maduración, pero escrita casi a vuclapluma en cinco o seis meses. En ella se hace un análisis Irascendental del conocimiento: ¿Cómo son posibles las ciencias? ¿Cuáles son las condiciones de posibilidad del conocimiento? A modo de introducción a su obra, escribe Prolegómenos a toda metafisica futura (1783). Publica Idea para una historia general 'oncebida e'n un sentide) cosmopolita (1784); Respuesta a la pregunta: iQué es la ilustración:' (1784); Fundamentos de la metafísica de las costumbres (1785), en la que trata del uso práctico de la razón pura. En 1786 es nombrado recior de la universidad, cargo que implical hacerle un homenaje al rey Federico Guillermo II. En este año publica Fundamentos metafisicoss iniciales de la cosmología.

En 1788 publica su olra gran obra: Crífica de la rasón práctica, cuyo Iema es la vida moral del hombre libre. Esice mismo año es nombrado rector de la Universidald de Königsherg por segunda ve\%. In 179() publical (rítica del juicio, que intenta mediar entre naluralezal y libertad, o armonizal las dos Críticas anteriores. Lis decano de la Iaacultad de Iïilosolḯa en 1792. Escribe La religión dentro de los limites de la mera razoin (1793) y El fin de todas las cossas (1794),

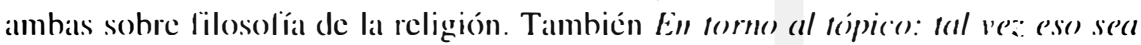

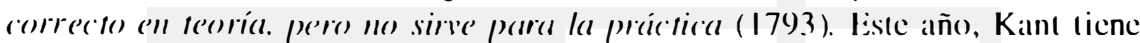
un confliclo con la censura de Prusia, prohibiéndole escribir o dar clases sobre lemas religéosos. A partir de entonces Kant reduce su actividad académical en la universidad, hasslal cue se redira de la acdividad docente en 1797. Publica Por la par perpertuca (1795); Méfafisica de las cosmumbres (1797), obra sobre lilosolía del derecho y de la moral, y gue hay que distinguir de la anterior fimmlamementeión de la métefisica de las costmmbres que introduce a las leorías élicas de la Crítica

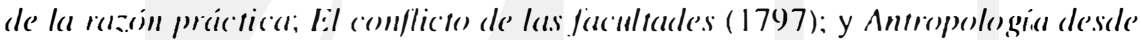

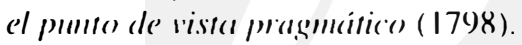

I 18()() $\mathrm{K}$ inl va debilitíndose poco a poco. In discípulo suyo, Wasianski, se ocupa de su cuidado. In octubre de 18()$_{3}$ sulie una apoplejia leve. Muere el 12 de lichrero de 18() 4$.

\section{Los escritos políticos de Kant}

\subsection{Hi cuerpo de sus obras}

Kant es reconocido principalmente por sus lres (irficast. cyue constituyen la base de su pensamiento. Sin embargo su obra completa es extensa y abarcal otros campos de estudio como el derecho, la polílical, la historia, la religión y, lïnalmente. la antropología. Muchos de estos estudios no constituyen formalmente libros exicnsos, sino yue son apenals "opúsculos" o "escritos menores", sin desacreditar lo lirmemente lundados en que se encuentran. Hay gue reconocer además (jue la producción kantiana puede interpretarse en dos elapas: la pre-crílical. hasta 177(), y la crílica, hasta su muerte. Proponemos a continualción un listado

Los escritos políficos de Immanuel Kant 
del conjunto de las obras de Kant, para luego proceder a referirnos a los escritos políticos en específico.

1749 İdeas sobre la verdadera valoración de las fuerzas vitales

1755 Sobre el fuego;

Principios fundamentales del conocimiento metafisico;

Historia general de la naturaleza y teoria del cielo

1756 Sobre la monadología física

1762 La falsa sutileza de las cuatro figuras del silogismo;

El único argumento posible para demostrar la existencia de Dios.

176.3 Estudio sobre la evidencia de los principios de la teología y la moral naturales;

Ensayo para introducir el concepto de magnitudes negativas en filosofia.

1764 Observaciones sobre el sentimiento de lo bello y lo sublime;

Ensayo sobre las enfermedades de la cabeza.

1766 Sueños de un visionario esclarecidos por los sueños de la metafisica.

1770) Disertación sobre la forma y los principios del mundo sensible e inteligible.

1781 Ciricica de la razoin pura

178.3 Prolegomenos a toda metafísica futura

1784 Idea para una historia general concebida en un sentido cosmopolita; Respuesta a la pregunta: ¿Qué es la ilustración”

178.5 Fundamentos de la metafísic a de las costumbres.

1786 Findamentos metafísicos iniciales de la cosnologia.

1788 Crítica de la razón práctica.

179) Crifica del juicio.

179.3 La religion dentro de los límites de la mera razinn;

En torno al tópico: "Tal vez eso sea correcto en teoria, pero no sirve para la práctica".

1794 El fin de todas las cosas.

1795 Por la pas perperua.

1796 Metafisica de las costumbres; El conflicto de las facultades.

1798 Amtropologia desde el punto de vista pragniático.

\subsection{Los escritos políticos}

Para exponer los escritos polílicos de Immanuel Kant me ceñiré a la selección de textos yue propone Hans Reiss en su libro Kant's Political Writingss. Desgraciadamente esta selección de "escritos políticos" no se halla reunida y editalda en español. De hecho, la edición de Hans Reiss es la primera que apareee en lengua inglesa y consiste en aquellos escritos que talan explícilamente la leoría política y gue lueron puhlicaldos en vida de Kant. Reiss ha excluido aqueIlos ensayos que trallan marginalmente lo políticot, tales como Probable inicio 


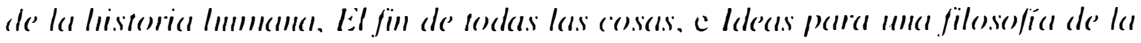
histerrica de la lmmmenteded, pero ha incluido una breve pero esencial parte de la

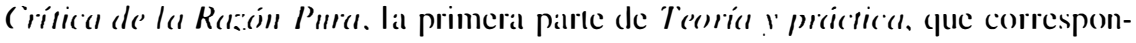
de a la élica. y algunos liagmentos de Metafisica de las costumbleres y del Comflicere de las facultadess en lo que se reliere a la relación entre libosolía y polítieal, excluyendo lo relerente a las otras laculades (teología y cienciass). I a razón yue da de ello es porgue "de lo contrario, hubiera distraido la alención hacia el objelivo principal de este volumen"7. Reiss lambién ha excluido los pasajes políti-

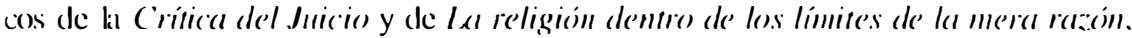
así como un breve apéndice de los elementess metefísicos del bienn. A esta exclusión se reliere así: "en ninguno de los caisos se ha omitido algo substancial. Kant solamente está repiliendo puntos cue hat hecho en otra parte“”. $\Lambda$ su ve\%. hal excluido las notas sobre polítical que aparece en los estudios preliminares de Kant que aparecen en los volúmenes XXII y XXII de Akedelemiecensissale" y en el lomo I.I de Kant-Sindient, debido a cue Kant no los había publicaldo, sino que son publicaciones póstumas. Reiss señala gue en todo caso no olrecen nada dilerente de lo dicho en lo publicado y gue son a menudo horradores, notas, comentarios en libros cue estiaba leyendo, ele'"1".

En conclusión, Reiss propone la siguiente selección de escritos que conlorman el conjunto sustancial del pensamiento polílico de Kant:

- Ideas para mana historia universal en clene cosmopolita ( 1784)

- Ima respmesta a la pregunta: ¿Qué es la Ilustraciom? (1784)

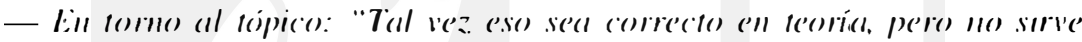
para la pricictica" (179.3)

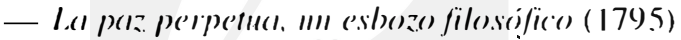

- Merafisica de las costumbres (Iragmentos) (1797)

- El comflicto de las facultades (1797)

- Critica de la Razin Pura (Fragmento) (1781)

\subsection{Kant como pensador político}

Immanuel Kant no es conocido como pensador polílico. Normalmente suele ser identilicado a sus tres Críticas y es estudiado, sobre lodo, en metalísica. epistemología y lilosolía de la religión. En libosolía política no hay un lugar para él. Fssto se debe, en parte, a cue electivamente sus Ires Crílicas absorben casi totalmente la atención de la tradición lïlosólica. Otra cosa luera si Kant hubiese escrito una obra grande y completa sobre teoría polílica, pero no escribió sino pequeños ensayos. Incluso, ha dado más rellexión a la Filosolía del derecho con su obra Elementos metafísicos del bien. Otra razón para considerar la poca popularidad de Kant es su estilo de no lácil lectura".

Los escritos políficos de Immanuel Kant 
Si nos lijamos en las lechas de publicación podemos constalar que los escritos polílicos" de Kant pertenecen a la madurez de su pensamiento. Kant estaba sobreslos sesenta años cuando empezó a publicar sobre algunos elementos de teoría política y. en la medida en que envejecía, aumentó este tipo de publicaciones. Sin embargo, es una aberración pensar que Kant se preocupó de la polílical únicamente en la última década de su vida. Esio no es así, y la prucha de ello es que se conocen notas donde sostuvo por largos años preocupaciones lecóricas sobre acontecimientos políticos y sobre teoría política en general. La nota mís remola data aproximadamente a 1760) cuando estudiaba a Rousseau y el derecho nattural. Iss importante considerar que el pensamiento político kantiano se halla en total correspondencia con sus tesis epistemológicas y éticass suscritas en las ('ríticals y, por lo tanto, estín rigurosamente lundamentadas por los límiles acotados en ellas, y esto constituye en sí su mayor mérito.

Por otro lado, el pensamiento político de Kant está luertemente inlluenciado por dos hechos históricos propios de la épocia: la Revolución I'rancesa (1789) y la Independencia de los Is:stados Unidos (1776). No en halde ha sido calilicado por Heine, primero, y luego por Marx y Engels como el lilósolo de la Revolución lirancesal. Hay cierta analogía entre ambas revoluciones y el pensamiento kimtiano: la independencia del individuo frente a la autoridad y el problema de la libertad, que yacen en el eentro de su pensamiento, guardan coherencia con la reivindicación de ambas revoluciones de la realización de los derechos del ser humano. Sin embargo, ya hacia 1784 Kant venía pensando sobre estos temas propiamente políticos. I:s posible considerar, con todo, que la Revolución Francesa lo estimuló a seguir escribiendo. Esto se inliere porque lanto la Revolución Francesa como la Independencia de Estados Unidos abrieron la mente polílica de la épocal. secularizándola. Ahora bien, si es cierlo que, en muchos calsos, Kant se acerca a los ideales de la Revolución Francesa, su demanda de par. perpelua va mucho más lejos que ella.

lals ideas políticas de Kant se enfrentan a los clásicos iusnalturalistas como Hobbes, locke, Hume y Rousseau, y al realismo político de Maquiavelo. También se enfrentan las tesis de sus contemporáneos, J. Hamann y J. Gotlfried, quienes sostenían una crítica al clamor de la Ilustración de descubrir principios universales válidos y el ver la historia y la sociedad en téminos de regular unilormidad. Para ellos, el individuo era más revelador y no se podía subsumir a leyes generales. Kant les responde en lorma cientílica y lógicamente riguroso lo que ellos criticaron, delendiendo la Ilustración como un proceso dinámico, como una negación a lodo lipo de estancamiento. En este sentido, el pensamiento de Kant se suscribe en dicha llustración. Kant es su madurez, pero lambién su mejor críticia.

Tras Kant, Friedrich Schiller y Wilhelm von Humboldt sostuvieron que su teoría polílica no prestó atención a la hase psicológica de las decisiones polílicas 
y que necesitaba complementarse con un estudio del carricier humano. Kant lue lenido por los romínticos alemanes como su archienemigo. läichte y Schelling, y después Hegel, lueron lotalmente en contra de lass lesis polílicals de Kant, y pusieron encima del individuo un yo-pure y un yo-ibsoluto (jue devenía en la historia. La joven Marx, más aldelante, se dejó impactar por lass ideals políticas de Kant, sobre lodo en acjuella gue señala gue el hombre es un proceso inacabado de ilustración.

\subsection{I as ideas políticas de Immanuel Kant}

In primer lugar. considero lo enormemente sugerente gue es la lectura de los escritos políticos, sobre lodo en el aclual contexto de guerra. pero lambién de globalización y de poner en ela de juicio la ideal de progreso de la humanidad hacia mejor. I a rellexión kantiana sobre estos temas no han perdido actualidald.

Solore la base de lo lédo, desarrollaremos las siguientes temailicas: (a) las disposiciones de la Nalluralezal; (b) antagonismo e Ilustración; (c) el problema de la libertad y la necesidad del derecho; (d) revolución y evolución: (e) relaciones internacionales y parz: (l) utopismo crílico.

\section{(a) I as disposiciones de la Naturaleza}

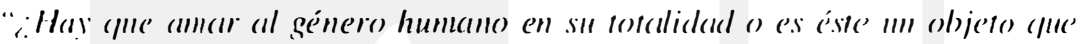

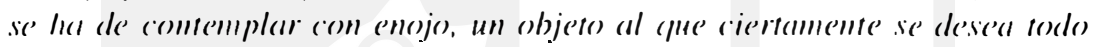

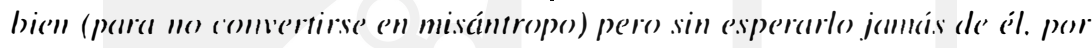

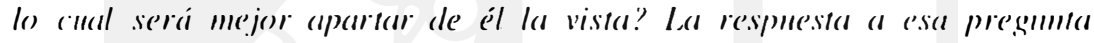

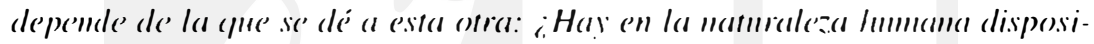
ciones de las cuales se puede desprender ane la espescie prongresara siempre

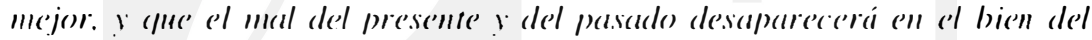
fittirlo?" "I?

Kant se preocupa por encontrar una hase lirme paral echar a andalr su sistema polílico-libosólico. İrente la postura de los contractuallistats. Kant sostiene que esta base no puede ser delinilivamente el lin particular de calda ser humano, como tampoco el lin general, dehido a la dilicultad del consenso. I a Nalluralesa es para Kant esta hase desde donde se garantizal, por ejemplo, que la historia humana progrese hacia mejor y gue la par. seal perpelua. Pero no nos apresuremos. In Ideas para una historica universal e'n clave cosmopolita, escrito en 1784, Kant se propone explicar como, independientemente de consideraciones metalísicals sobre la liberlad, las acciones humanass se hallan determinaldals a leyes universales de la Naturaléa. Para ello el libósolo deberí intentar descubrir "en este absurdo de las cosas humanas una intención de la Naluraleza" A lo largo de los nueve principios del ensalyo en mención irá delermunando cómo la naturaleza dispone sus designios para hacer que la historia progrese: el prime' principio sostiene el carácter teleológico de la Naturalezal, todo responde según la Naturaleza a una linaliclad; el segunde principios hace ver que en el ser huma-

Los escritos políticos de Immonuel Kont 
no. el único ser racional, la plenitud de su naturalèa no se desarrollará en el individuo, sino en la especie, y esto sobre la base de experimentos, tanteos y crrores de los seres humanos, de donde también se sigue que la razón es una herencia de la especie, más (que del individuo ${ }^{14}$; el tercer principio propone que el hombre alutónomamente tiene que hacerse la vida, esto por designio de la Nalturales at el cluarto subraya el carácter antagónico (la insociable sociabilidad, que abordaremos mejor en el siguiente apartado) que ha propiciado la Naturaleza para (lesarrollar las disposiciones humanas; el quinto principio es cómo la naturaleza le luer al al hombre (debido a su problemática libertad) a vincularse recíprociamente mediante la instaturación de la sociedad civil y la valide\% universal del derecho; el sex/o principio pone un realismo utópico al señalar lo tardío y elímero de esa constitución civil y (lerecho universal; el séptimo sugiere de nuevo que la Naturalea ha dispuesto en su antagonismo el medio para instaurar la paz; el octavo principio dice que la historia es la ejecución del plan oculto de la Naturalèa, que poco a poco val emergiendo la ilustración y que la Naturalezal alberga un estado cosmopolita1‘: por último, el principio noveno lo dedical a considerar el uso práctico de esa intención de la Naturaleya como "hilo concluctor" que alumbrat el calmumar, es decir como una construcción utópica válida y necesaria.

Como hemos podido apreciar, este ensayo (Ideas parc una historica universal ('n clave cosmonolita, 1784) precede a la Crítica de la Razón Práctica y a la (iritica del Juicio, y lleva en sí la gran varielad de lemas que Kant prolundizará en sus escritos posteriores. Su preocupación por demostrar que en la base están los designios ocultos de la Natturaleza, lo lleval a argumentar a lavor de la razón humana, de la historia que evoluciona realizando tales designios, el carácter antagónico de esa praxis y la necesidad de la razón de pensar este horizonte utópico para ayuclar a la misma Naturaleza.

Lin el arlículo Una respuesta a la pregunta: ¿Qué es la Ilustración?, publica(lo también en 1784, dice que el uso de la razón es una disposición de la Naturalezal a los seres humanos y que ir en contra de esto es ir en contra del lin que la Naturalezal le ha prescrito al hombre. Podríamos decir entonces que Kant utiliza la Naturalèa como instrumento de valoración ética, por ejemplo cuando dice: "constituiría esto un crimen contra la naturaleza humana, cuyo destino primordial radical precisamente en este progreso"'l6.

De nucvo el tema (le la Naturaleza se tratará en el ensayo titulado En torno al rópico: "Tal vez eso sea correcto en teoria, pero no sine para la práctica", escrito en 1793. Ese tema se aborda, sobre todo, en la tercera parte, cuando propone que la naturaleza es la que garantizal el progreso de la historia humana: "Si preguntamos ahora por qué medios cabría mantener, e incluso acelerar, este incesante progreso a mejor, pronto se ve que tal éxito no dependerá tanto de lo que hagamos nosotros (por ejemplo, de la educación que demos a la juventud) y lel mélodo con que nosotros hemos de proceder para conseguirlo, cuanto de lo 
que haga la naturaleza humana en nosotros y con nosotros para forzarnos a seguir una vía a la cue difícilmente nos doblegaríamos por nosotros mismos"17. Esta galrantía (que olrece la Nalluraleza para el progreso de la historia humanal a mejor, lambién lo olirece para la consolidación de la par, perpelua, tal y como lo vemos en el artículo de ese nombre. En el suplemento segundo del artículo recién mencionado, Kant se propone "examinall el estado que la nalturalezal hat organizado para la paz, perpedua" y "el modo en que suministra lal garantía". Aunque estos temas seraín abordaclos en apartados siguientes, podemos adelantarnos a decir cue la Nalluralezal garantiza la paz perpetua mediante tres instiluciones: la legislación universal (algo así como el gobierno de los derechos humanos). la diversidad de culturass y creencias, y las relaciones comerciales. Sirva la siguiente cila para dejar claro a qué se reliere Kant cuando dice que la garantía del progreso y la par es la Nalluralezal:

"Cuando digo (pue la naturalesal cpuicre gue ocurra esto o acjuello no signilica (jue la naluralezal nos impongal un deber de hacerlo (pues esto scílo puede imponerlo la razón práclica libre de coacción) sino yue ella misma lo hace, (jucrimosimo nosotros o no" ${ }^{\text {"1x. }}$.

I n resumen, la Naluralesa en la teoría de Kant cumple básicamente lres lunciones: primero, lleva en sí misma el designio leleológico de realizarse a plenitud (lo cual podría debatirse, es decir, es un presupuesto injustilicado pensall yue el plan oculto de la Nalluraleza —si lo hubiere- debe realizarse: la práctica capilalista del último siglo ha demostrado gue se puede caminall irracionalmente consumiendo lodos los bienes de la Nalturalezal y acabal completamente con la misma, esto sin pensal en un apresuramiento mediante la utilización de bombas alómicas, por ejemplo); segundo, como valoración élica en el sentido (jue no se debe ir en contra de la Nalturalesa, ni sicpuiera es permilido estancarse: y lereero, como garantía del progreso humano hacia mejor y de la par perpelua.

\section{(b) Antagonismo c ilustración}

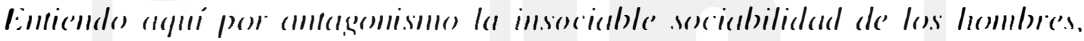

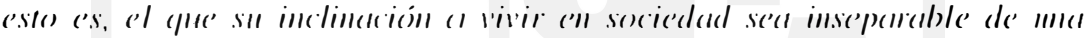

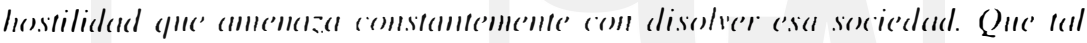

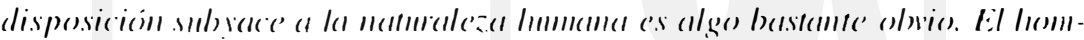

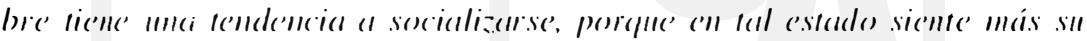

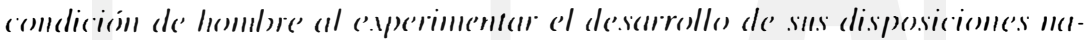

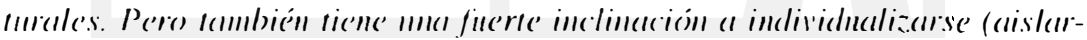

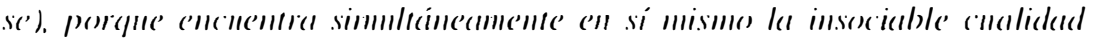

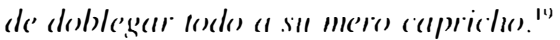

Para Kant, el antagenismo es el medio del gue se sirve la naluralesa para hacer cue los seres humanos lleguen a un orden legal donde puedan realizarse

Los escritos políticos de Immanuel Kant 
como lines en sí mismos, y no solamente como medios ${ }^{20}$. Por antagonismo, como se lec arriba, se reliere a la "insociable sociabilidad" de los seres humanos. Para Kant la resistencia a la sociabilidad despierta todas las fuerzas del ser humano y las desarrolla, "dejando la inclinación a la perèa e impulsándolo a la ambición. al alán de dominio o a la codicia”. Descle esta noción, Kant argumenlará cómo desde liempos primitivos el hombre ha venido desarrollándose a tratvés de guerras y competencia, hasta alcanzar la ilustración y el discernimiento élico. De no haber sucedido así, y de no disponer la Naturaleza de lal antagonismo, los talentos hubicran cyedado ocultos y los seres humanos serían animales domésticos nomís y jamaís "hubieran llenado el vacío de la creación respecto de su destino como natturaleza racional". Tal antagonismo además revela hien "la organización de un sabio creador, y no algo así como la mano chapucera de un genio maligno que arruinaría su magnílico dominio por pura envidia".

lil antagonismo es el molor del progreso de la historia en Kant. pero lambién lo será posteriormente en Hegel, donde la negalividad es un momento del desalrollo del $\Lambda$ bsoluto, y en Marx, gue acuña el lérmino de "lucha de clases".

Para Kant, el úllimo estadio de este antagonismo es la ilustración. Poco a poco va emergiendo la ilustración, "como un gran bien yue el género humano ha de oblener"-1. I a ilustración es sobe lodo "la liberación del hombe de su culpable incapacidad".:- és pasar a la edad adulta y dejar la inlancia como algo del pasado, es anriesgarse a pensar, permilirse tal aventura. De la ilustración lambién se puede decir de lo gue se ha dicho de la Nalturalezal, es decir, que constiluye en si mismo un lin teleológico (todos caminamos hacia la ilustración. auncpue no riamos en una época ilustradal) y una obligación élical (a cuya realización estatmos obligados y no podemos permitir su estancamiento).

lin resumen. para Kant, en virtud de la insociable sociabilidad humana, han sido necesarias las guerras y las dispulas sociales para que el hombe comprenda que dehe hasaar sus acciones en la razón que ordena a priori los imperallivos cillegoricos del deher ser. Desde el antigenismo humano, nace entonces el deseo de erigir un sistema legal y una constitución civil cue de pie a la míxima realizatcion de calda individuo dentro de la sociedad. Así nace el derecho, la consilucion civil, la contederación de estados y la paz perpelua. Esios son produclo de mentes ilustradas. del acuerdo de personas gue se dejan guiar por los preceptos yue le diclal su rarón.

\section{(c) El problema de la libertad y la necesidad del derecho}

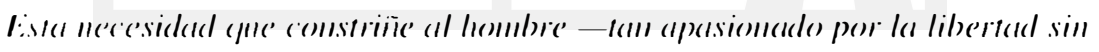

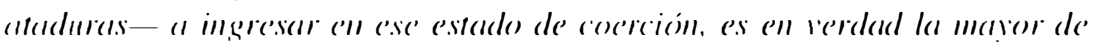

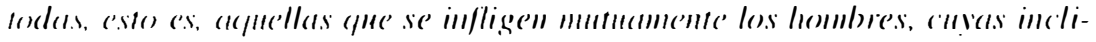

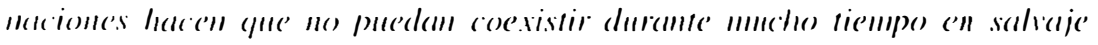

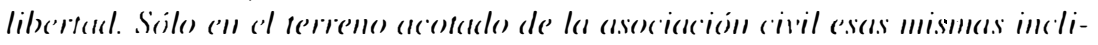

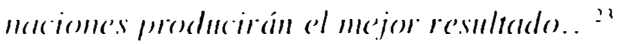


Kant concibe la sociedad como "libertad hajo leyes externas". Es decir, que el antagonismo en que se encuentra el ser humano lo obliga a entrar en una constilución civil que ejerza coerción cuando las exageraciones de mi liherlad empiecen a dañar la libertad de los demás. La naturaleza, siguiendo el argumento kantiano, ha dispuesto en el hombre de lal libertad, que su exceso sería el conflicto entre unos y otros hasta el acabose, por lo que hay que seguir los dictados de la razón (de la Ilustración) y acordar muluamente en pro de una sociedald civil regida por leyes, cuyo papel sea contener y ejercer coerción conIra csos excesos de la liberlad. Ya desde la Crítica de la Razim Pura, en I78I, Io ha dicho:

"Una constitución que permita la máxima libertad humama de acuerdo a leyes que establezcan que la libertad de cala crual pueda conexistir con la de los demás (no de la máxima lelicidad, pues ésta ya vendría por sí misma como consecuencia), es por lo menos una idea necesaria que liene que servir de hase, no sólo en el primer proyecto de una Constilución del listado, sino lambién en Iodas las leyes" 24 .

Más adelante, en Hacia la pa: perpetua, Kant se ceñirá a las elaboraciones teóricals de Hobbes y locke y dirai que el estado de naluralezal del homberes el de la guerra: "I l estado de paz entre hombres que viven juntos no es un estado de naluraleza, que es más hien un estado de guerra, es decir, un estado en el que, si hien las hostilidades no se han declarado, sí existe una constante amena-

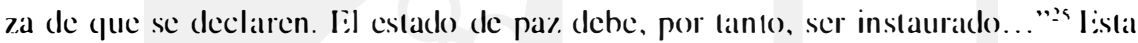
última liase es muy reveladora. El Estado "debe ser instaturado" signilica cpue es una larea de los hombres y que la concpuista del derecho es la constilución misma de lal listado. Estos son los gérmenes que subyacen en la épocal para la instauración de un Isstado de Derecho, es decir de un Estado regido por leyes.

İ problema ahora consiste en considerar cuáles son los liundamentos y los cribrios últimos para diclar leyes de carácler universal. I a obra élica de Kant intental dar respuesta de manera completal a esta lundamentación necesaria, sin embargo por el momento nos contentaremos con las conclusiones gue llegal en su

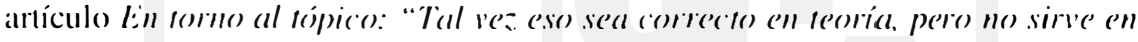
préctica". I:n la primera parte de este ensayo, en el que trata la relación leoría y práctica en moral. Kant sostiene gue no debemos lundamentar las leyes eniendo como criterio la lelicidad, ni sicpuiera la ledicidad de un pueblo, pero lampoco la moralidad como tal, como se ve cuando dice: "el único lïn del Creador no es ni la moralidad del hombre por sí misma, ni la lelicidad sola, sino el supremo bien posible en el mundo, que consiste en la reunión y concordancia de ambas" "z". Ahora hien, sabiendo cue la linalidad última es el bien supremo, es decir la máxima lihertad mía coexistiendo con la máxima libertad de los demás, Kan sugiere que actuemos de acuerdo al deber y no a la lelicidad: "el ser humano puede y debe hacer el hien de manera pura (es decir, sin otros móviles) y luego

Los escritos poílicos de Immanuel Kant 
gustar de la felicidad o la inlelicidad que ello le cause"27. La felicidad es equívoca y, en todo caso, secundaria, ya que no garantiza el supremo bien, sino apenas hienes personales.

En "la segunda parte del ensayo en cuestión, que trata de la relación entre teoría y práctica en el derecho, Kant se pronuncia en contra de Hobbes. Para éste, el Estado civil es un medio para garantizar el desarrollo de las libertades y derechos individuales. Para Kant, por el contrario, el Estado civil es un fin en sí mismo. ya que a través de él se plenifica la especie humana. Si el "contrato social' de Hobhes es unión de personas en orden a cualquier fin, la 'constitución civil’ de Kant es unión de personas como fin en sí mismo. De este modo, para Kant, la sociedad no es una suma de individuos, sino comunidad, y he aquí una de sus velas revolucionarias entre las teorías políticas clásicas de la época.

Palla Kant, Ios principios a priori del estado civil son la libertad, la igualdad y la independencia. El Estado civil que Kant tenía en mente no es el 'Estado paternalista' que actúa con el puchlo como si éste luera menor de edad, como un pucblo pasivo que esperal el deber ser del mandalario. Todo lo contrario, Kant piensa en un "Isstado paltriólico" donde los hombres sean capaces de tener derechos, donde sean libres en la prosecución de su lelicidad sin interlerir con la de los demás. Tal Lsiado deherá tener en igualdald de coacción a todos sus súhditos, todos deherán estar ceñidos a la ley que coacción los excesos de lihertad. Es una igualdad jurídical, de coacción, que es a su vez compaltible con las demás desigualdades (económicals. culturales, etc.). Por último, la independencia que en mente de Kant se reliere a la capaciclad de calda cual de subsistir, es decir que calda quien tenga los medios y la propiedad necesaria para hacerse carge de sí mismo. La independencia así entendida puede resultar ambigua: por un lado puede ser una postura "conservadorä si acoge en su seno únicamente los que tengan "propiedades", pero por otro lacto. y pienso que éste es el calso de Kant, es una postura 'liberal' en tanto que sugiere un orden social donde cada quien pueda hacer su vida y realizarse como persona. Por lo menos, ésta es la idea de la constilución republicana que Kant sugerirá una y otra vez como la más adecuada para alcanzar el lïn indicado.

Concluye, pues, así:

"Resulta claro que el principio de la felicidad (propiamente incapaz de conslituirse en aluténtico principio) también conduce al mal en Derecho polílico, tal y como lo hacía en Moral, por óptimal que sea la intención que se proponen sus (lelensores. Ll soberano quiere hacer leliz al puchlo según su concepto, y se convierte en déspota. El puchlo no quiere renunciar a la general pretensión humana de ser leliz, y se vuelve rehelde. Si se hubiese preguntado, ante todo y sobre lodo, qué es conlorme a (lerecho (aquí los principios están lijados a priori y ningún empírico puede hacer chapucerías), la ideal del contrato social manten(lría su indiscutible crédito; pero no como un fac flum, sino sólo como principio racional para juzgear toda constitución jurídica púhlica en general"”-2x. 
Ien resumen, para Kant, el derecho es la limilación de la liberlad de cada uno a la condición de concordancia con la libertad de lodos, en lanto que universalmente posible. I:I predominio del derecho en la teoría polílica kantiana responde sobre lodo a su fundamentación élica. Más adelante se relerirá, por ejemplo, a la imposibilidad de la revolución de un pucblo contra su lirano. pero lambién a la constitución de un Derecho internacional, al que llama ya no derecho público (yue es el derecho dentro de un Estado civil delerminado), sino derecho de gentes (yue se rige por los principios universales de la hospitilidad).

\section{(d) Revolución y evolución}

"Toda oposicioin comera el supremo poder legislationo, toda incitación que

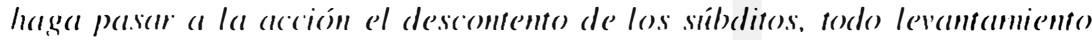
ance astalle en rebelión. es el delito supremo y mais punible en una communi-

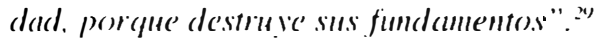

Lstas palabras parecen demasiado luertes y demasiado conservadoras, sobre lodo cuando los lundamentos de una sociedad delerminada, por qué no decir de la nuestra, se han erigido sobre la hase de injusticias. opresión. excelusión y desigualdad. Sin embargo. nos hallamos con un pensador político de la Ilustratción de hace poco más de doscientos años altrás y, a nuestro modo de ver, no poco revolucionario y vamos a ver por qué.

En primer lugar recordemos que Kant es un gran humanista y lo que le preocupa es la instauración de un reino donde los hombres scean lines en sí mismo. y no simplemente cosas o medios de cualquier sistema. Para la instiuratción de este reino, Kant ve que la naturaleza ha dispuesto en el hombre el uso de lat rarón. Ante el desagrado de lantas acluaciones humanas irracionales, no le queda más que encontrar en el derecho la realización de un orden donde la máxima libertad personal coexista con la míxima libertad de los demás. El reino de los lines, en Kant, es el Estado de derecho y a esto se alerra, pero si se destruye el derecho entonces queda nulo el reino de los lïnes y, por lanto, la realización humana. Por otro lado, las irrupciones al orden legal responden no lanto a la consecución racional de mejorar tal orden legal, sino a los caprichos del ser humano de perseguir sus propios intereses y su propia felicidad, y ya vimos (jue la lelicidad no constituye un principio de derecho político. La lelicidad de un puchlo, en lodo caso, es el lermómetro de la actuación del gohernante, de donde se sigue que "diclar leyes orientadas a la felicidad se hace más bien para conservar y asegurar el estado de derecho y procurar que exista la comuni(lad, sobre lodo liente a enemigos exteriores del pueblo" ${ }^{\text {? }}$.

Si bien es cierto que la felicidad o infelicidad de un pueblo no puede ser causa justilicatoria de una revolución, tambićn es cierto que son los mandatarios los que propician las condiciones y las causas de la revolución:

Los escritos políticos de Immanuel Kant 
"Ascguran (nuestros politicos) que se ha de lomar a los hombres lal como son y no como los pedantes que no conocen el mundo o los ilusos hienintenciorsaldos dicen que deben ser. Pero ese comos son viene a signilicar en realidad: lo que nosotros hemos hecho de ellos mereel a una coacción injusta y mediante alevosas macuinaciones inspiradas por el gohierno, esto es, seres obstinados y proclives a la rebelión; así las cosas, por supuesto que si allojan un poco las riendas, acontecen trigicas consecuencias que cumplen los valicinios de acyuellos estadlistas presuntamente perspicaces"

Pero en ves de una revolución, Kant habla de ayudar, por medio de la razón, a que la hisloria humana evolucione hacia mejor; es decir, en ve\% de revolución. propone evolución". Listo no indica que deha ser visto como un "lameholas" (lel sistema y del monarcia, ante lo que se defiende:

"Mas, si a la vista de estas afirmaciones mías no se me hará, a huen seguro, el reproche de que con tal inviolabilidad lisonjeo en exceso al monarca, cabe esperar que se me ahorre el reproche de que lavoresco demasiado al puchlo cuando digo que éste liene. igualmente, sus derechos inalienables frente al jele de listado, auncjue no puedan ser derechos de coacción"'?.

Kant se reliere principalmente a una evolución ilustrada donde debe prevaleeer a toda costa la libertad de pensamiento y la liberdad de expresión:

"Por lanto, puesto que lodo hombre liene, sin embargo, sus derechos inalienables, a los que ni puede renunciar aunque quiera y sobre los cuales él mismo está lacultado para juzgar, y puesto que, por otro lado, la injusticia que en si opinión sulre proviene, según esa hipótesis, del crror o del (lesconocimiento de ciertas consecuencias de las leyes por parte del poder supremo, resulta que se ha de otorgar al ciudadano - y además con permiso del propio ciucladano - la facultad de dar a conocer públicamente su opinión acercal de lo que en las disposiciones de ese soberano le parece haber de injusio para con la comunidad. Pues admitir que el soberano ni siquicra puckle equivocarse o ignorar alguna cosa sería imaginarlo como un ser sobrchumano dotado de inspiración celestial. Por consiguiente, la libertad de pluma es el único paladín de los derechos del pueblo (siempre que se mantenga dentro (le los límites (lel respelo y el amor a la constitución en que se vive, gracias al modo de pensar liberal de los súhditos, también inculcado por esa constilución, para lo cual las plumas se limitan además mutuamente por sí mismas con objelo (le no perder su lihertad)"34.

Más adclantc, en El conflicto de la facultades, de 1798, Kant ve que la idea (le progreso hacia mejor y cvolución, no sólo cultural sino también moral, es una tendencia del género humano, y lo cjemplifica con la Revolución Francesa:

"La revolución de un pucblo pletórico, que estamos presenciando en nucstros días, puede triunfar o fracasar, pucde acumular miseria y atrocidades en 
lal medida que cualquier hombre sensallo nuncal se decidlese a repelir un experimento lan costoso, auncpue pudicra llevarlo a cabo por segunda vez con lundadas esperanzals de éxilo y, sin embargo, esa revolución - a mi modo de ver- encuentra en el ánimo de lodos los espectadores (que no estín compromelidos en el juego) una simpalía rayana en el entusiasmo, cuya manifeslación lleval aparcjado un riesgo. (jue no puede lener otra causa sino la de una disposición moral en el género humano" "s.

lin ese texto. Kant señala "la evelución de una constitución iusmenturalista gue, auncpue se concjuiste en medio de brutales contiendas, nos hace aspirat a una constitución (jue pueda no ser hélical. es decir, la republicanal" "De lal manera, yue el deber ser se postule asi: "I In loda comunidad liene gue haber una obediencia sujeta al mecanismo de la constilución estallal, con arreglo a leyes coactivals (gue conciernen a lodos), pero a la ves liene gue haber un espírilu de liberlad. pues en lo cue allañe al deher universal de los hombres lodos exigen ser persuadidos racionalmente de gue lal coacción es legílima, a lin de no incurrir en contradicción consige mismos" $"$.

\section{(c) Relaciones internacionales y paz}

Si se comprara con ello la conducta inhospitalaria de los Estados civilizados de mestro continemte, particularmente de los comerciantess, produce espanto la injusticia que ponen de manifiesto en la visita a paries y pueblos axtranjeros (para ellos significa lo mismo que conquistarloss). America, los paises negros. las Islas de las Especies, El Cabo, etc., eran, para ellos, al descrubrirlos, porises ance no pertenechian a nadie, pues a sus habitantes no los remian e'n rue'ma para nada. En la Indias orientales (Indostain) introdujeron rropas extranjeras, bajo el pretexto de establecimientos comerciales, y con las tropas introdujeron la opression de nativos, la incitacioin de sus distintos Estados a stande's guerras, hambrunas, rebelión, perfielia y cuanto figure en la lesania de todos los males que afligen al género humano. "

No está demás empezar esie apartado considerando la fuerte crílica cue Kant le hace a las naciones curopeass y su política exterior. Sin duda, esta crílica no ha perdido actualidad, auncjue también deba ampliarse a otros países no curopeos.

Hay tres ensalyos en los que Kant trata de la problemálica de las relaciones internacionales y la paz: Ideas para una historia universal en clave cosmopolita; En tormo al tópico: "Tal vez eso sea correcto en teoría, pero no sirve para la práctica", y Hacia la paz perpetua. Este último es, sin duda, el mejor Irabajado. En él, enumera seis principios preliminares para la paz perpetua, ires artículos delinilivos, dos suplementos y dos apéndices, todos sumamente sugerentes. Demos una mirada aunçue sea un poco rápida.

Entre los principios encontramos: uno, la destrucción de las causas de la guerra y la claridad de intención; dos, cada Estado, sea grande o pequeño, es

Los escritos pofiticos de Immanuel Kant 
Independiente, no puede venderse ni entregarse en herencia ni unirse a otro Estado; tres, con el tiempo, los ejércilos deben desaparecer; cuatro, no debe emilirse (leuchí de guerra; quinto, un Estado no puede intervenir por la luerza en la constitución o gobierno de otro Estado"); y sexto, en caso de guerra, ésta debe limitarse y humanizarlo lo más posible a lin de generar confianza en el oponente en la lormulación de la paz lutura

lucgo de señalar que el estado de naluraleza del ser humano es un estado de guerra, Kant dice que el estado de paz. necesita ser instaurado, y propone tres arlículos delinitivos para la paz perpetua, a saber: uno, la constitución de todo İslado dehe ser republicana, es decir debe ser un Estado de derecho; dos, no debe haber un Estado mundial, ya que supone una relación superior-inferior, sino una 'Federación de estados libres'; y tres, el derecho cosmopolita debe ceñirse a las condiciones de hospitalidad universal, es decir a colaborar con los pueblos vecinos en sus necesidades de sobrevivencia. Aquí encontramos Irases muy elocuentes que prevén la mundialización y la globalización.

Posteriormente, añade dos suplementos para la paz perpetua, sumamente interesantes. En el primero de ellos Irala sobre cómo la Naturaleza garantiza el hecho que de un momento a otro se instiure definitivamente la soñada paz perpelua. Hay tres mecanismos que dispone la Naturaleza para garantizar dicha paz:

- Primero, la necesidad surgida en el seno de la liberad humana de que prevallexa la ley sobre los intereses personales:

"Pues hien, la constitución republicana es la única perfectamente adecuada al derecho de los hombres, pero es también la más difícil de establecer y, más aun de conservar, hasta el punto de que muchos afirman que tendría que ser un Estado de ángeles, dado que los hombres no están capacitado, por sus tendencias egoístas, para una constitución de tan sublime forma... El problema del establecimiento del Estado tiene solución, por duro que ello suene, incluso para un pueblo de demonios (siempre que tengan entendimiento)... la naturaleza quiere a toda costa que el derecho conserve, en último término, la supremacía. Lo que no se tiene el cuidado de hacer ahora, se hará finalmente por sí mismo, si bien con mayores molestias"40).

- Segundo, la división de pueblos en lenguas y creencias impedirán que haya un gobierno universal:

“... (la separación de mucho pueblos) es, sin embargo mejor, según la idea de la razón, que la fusión de los mismos por obra de una potencia que controlase a los demás y que pasara a convertirse en una monarquía universal, porque las leyes pierden su eficacia al aumentar los territorios a gohernar y porque un despotismo sin alma cae finalmente en anarquía... Sin embargo, la voluntad de todo Estado (o de su autoridad suprema) es llegar a la situación de paz duradera dominando a todo el mundo si es posible. Pero la naturaleza 
quiere olra cosa. Se sirve de dos medios para evitar la conlusión de los pueblos y dilierenciarlos: la diferencia de lenguas y de religiones; estas dilerencias llevan consigo, ciertamente, la propensión al odlo mutuo y a pretextos para la guera. pero, con el incremento de la cultura y la paulatina aproximación de los hombres a un más amplio acuerdo en los principios, estas diferencias conducen a coincidir en la paz, una paz generada y garantizada mediante el equilibrio (le las fuer/as en la más viva competencia entre las mismas, y no como resultado del quebrantamiento de todas las energías, como es el caso en el (lespotismo (en el cementerio de la libertad)"st.

- Y lerecro, la naluralesa dispone del espiritu comercial para unir a los demás puchlos que no eran protegidos en el derecho cosmopolita y en caso de guerra, se deberá acudir a los tratados de par. para reintegrar las relaciones comerciales:

"Se lrala del espíritu comercial que no puede coexistir con la guerra y que, inles o después, se apodera de lodos los puchlos"4?

Podría decirse entonces que la garantía de la paz perpetua que Kant en la Naturalesal. es la sujeción al Estado de Derecho; la diversidad de lenguals, culturas y ereencias; y las relaciones comerciales. Todo está perlectamente a lono con nuestra épocia. Podría decirse que los pasaldos atentados terroristass son los síntomas de un malestar más general ante la actual globalización neoliberal, y que es una especie de disposición de la Naturalera - siguiendo el argumento kantiano- para impedir el gobierno mundial de una potencia. Para Kant, lo que sí es cierto, es que las relaciones interestatales son entre iguales, y no de una relación de superior-inlerior.

I:I segundo suplemento es igualmente interesante y toca el papel de los lilósolos en los diversos momentos de la historia política y su relación con los gohernantes. Dice:

"No hay que esperar, ni que (lesear, que los reyes lilosolen ni que los lïlósolos sean reyes, porque la posesión del poder daña inevitablemente el libre juicio de la razón. Pero es imprescindible para ambos que los reyes, o los puchlos soheranos (que se gohiernan a sí mismos por leyes de igualdad), no permitan que desaparesca, ni que sea acallada, la clase de los libósolos, sino que puedan éstos hablar públicamente para la clarilicación de sus asuntos, pues la clase de los lilósolos, incapaz de handerías y alianzas de club por su propia nalluralezal, no es sospechosa de dilundir una propagandia ${ }^{\cdots+3}$.

lin conclusión, si hien todo esto nos lleva a pensar que Kant es un soñador demasiado ambicioso y hueno con la especic humana, por lo menos de su parte existe el alán de alumbrar la vida práctical y colidiana de los hombres y mujeres mediante el ejercicio de la razón:

\section{7}

Los escritos políticos de Immanuel Kant 
"Por mi parte, en cambio, confío en la teoría, pues ésta parte del principio jurídico de cómo debe ser la relación entre hombres y entre Estados, y recomienda a los dioses de la Tierra la máxima de proceder siempre, en disputas, de modo tal que con él se introduzca ese Estado universal de los pueblos, admitiendo como posible (in praxi) y como capaz de existir. Pero, a la ve\%, lambién conlío (in subsidium) en la naturaleza de las cosas, que lleva por la luer/a a donde no se quicre ir de buen grado. Y en la naturaleza de las cosas se incluye asimismo la naturaleza humana; como en esta última siempre continúa vivo el respeto por el derecho y el deber, no puedo ni quicro considerarla hundida en el mal es hasta el extremo de que la razón práctica moral, tras muchos intentos lallidos, no vaya a triunfar finalmente sobre el mal y no nos presenta a la naturaleza humana como digna de ser amada. Así pues, lambién (lescle el punto de vista cosmopolita se mantiene la tesis: lo que por lundamentos racionales vale para la teoría, es asimismo válido para la prácti(iil ${ }^{\cdots 1.14}$.

\section{(f) Utopismo crítico}

"Cuanto más de acuerdo con esta idea se constituyeran la legislación y el gobierno, tanto más raras serían en todo catso las penas y entonces es totalmente razonable (eomo alirma Platón) que no se necesitaría ninguna pena si ese Estado luera perlecto. Bien es verdald que esto último no puede realizarse nunca, pero es totalmente justa la ideal que erige ese máximum como prototipo para aproximar carla vez mís la organización legal de los hombres a la máxima perlección posible. Pues cuál sea el grado máximo en que quede necesariamente entre la idea y su ejecución, son cosas que nadle puede ni debe determinar, precisamente porque es la libertad la que puede rehasarr todo límite indicado" ${ }^{45}$.

Junto a éste texto de la Crítica de la Razón Pura, hay una gran cantidad de textos que nos permiten comprobar la veta utópica de la filosolía kantiana. Kant no obvia la realidad del ser humano y su imprescindible liberlad. El pensiamiento kantiano, hasta donde hemos visto, se apunta a la construcción de un reino donde los seres humanos, y la comunidad de ellos, sean lines en sí mismos; es una tareal. por su puesto, de ilustración, pero también de libertad de pensalmien10. de (leseo de pir y sujeción a un derecho público (orden nacional) y a un derecho de gentes (orden internacional). Aquí no sobra el papel de nadie, las personas como ciudadanos, los 'dioses de la Tierra' como mandatarios ilustrados, y los lilósolos como pensadores críticos y propositivos. Concluyamos este (:nsalyo con las mismas palabras de Rodrígue\% Aramayo:

"Todo el pensamiento práctico de Kant es esencialmente revolucionario, en cuanto nos marcal un horizonte utópico, unas metas prácticas cuya persecución irá remodelando el actual mundo lenoménico según el pattón eidélico aplicado. Una cosal es que siluado en la lógica inexorable del discurso jurídi-

\section{8}

Realidad 84, 2001 
co no reconozca un presunto derecho a rebelarse contra las tiranías y otra muy distinta que toda la filosolía práctica de Kant no presuponga una verdadera revolución, tanto en el orden moral como en el político, pese a que se trate de una empresa que resulte asintótica para sus agentes. Aunque las ideas encarnen una perlección que se sabe inalcanzable (Ak., V, 127n y Ak., VII, 199-200), nuestra larea ética es la de aproximarnos asintóticamente hacia esc horizonte de utopías ucrónicas" 4 .

O bien, éslas otras:

"Sin embargo, tal y como es concebida por Kant, la tarea del filósofo de la historia es genuinamente élica, pues consiste en modelar el porvenir a golpe de utopema. Ante la defensa del statu quo característica del político, el lilósolo debe acomeler una 'revolución asintótica', señalando por ejemplo el horizonte utópico de un estado cosmopolita, el cual, lejos de ser una quimera, ha de servir como paula para los principios de gobierno. Ni siquiera importa que se trate de una meta ucrónica; nos será útil en cuanto arquelipo al que ir aproximando la realidad. El quiliasmo lïlosófico liene la ventaja de verse propiciado por su propia idea. La herramienta lundamental del filósolo de la historia será, pues, la esperanza; con ella habrá de cincelar el perlil del luturo. No en vano, la esperanza fue homologada por la Crítica de la razón pura, a clecelos prácticos, con la lunción asignada al saber y a la ley nalural en el plano del conocimiento teórico.

"La sociedad - escribió Kant en una de sus Reflexiones-es comol la caja de Pandora. De ella surge el despliegue de todos los talentos y al mismo tiempo de lodas las inclinaciones; pero en el fondo subyace la esperanza". Y es que la esperanza era la única debilidad reconocida por Kant a la ecuánime e insobornable razón, representando una parcialidad que no podía corregir y que, por otro lado, tampoco le interesaba climinar.

$\Lambda$ buen seguro que Kant, auténtico adalid del utopismo ucrónico, suscribiría sin palialtivos estas líneas de Ortega, que tan bien sintelizan el espíritu del planteamiento analizado en estas páginas: "Normalmente los animales son felices. Nuestro sino es opuesto. [il destino - el privilegio y el honor- del hombre es no lograr nunca lo que se propone y ser pura pretensión, viviente utopía" (Miserica yesplendor de la traducción, ().C., V, 434)"47.

\section{Conclusiones}

- Iil estudio del contexto nos ha enseñado que la rellexión kantiana se halla a tono con las grandes ideas y hechos que caracterizan la edad moderna, a saber: por un lado, la crítica a la religión, la secularización del saber basado predominantemente en la razón, la emergencia del librepensamiento, la idea (ce progreso, la responsabilidad humana de dominar el mundo; y por otro

Los escritos políticos de Immanuel Kont 
lado, la mundialización de las relaciones cumerciales, el ascenso de la burguesía, la configuración de los Estados modernos, la expansión colonial, las relaciohes internacionales entre Estados y curocentrismo.

- El repaso de su biografía y obras han puesto de manifiesto los grandes intereses de la producción kantiana: la crílica a la metafísica y el asentamiento de las posibilidades y límiles del conocimiento científico, así como la descripción del imperativo categórico a priori que sugiere el deber ser racional en cada ser humano, en el ejercicio de su libertad. Además, demuestra su preocupación en abarcar sistemáticamente los distintos campos del saber: metafísica, epistemología, ética, religión, derecho, historia, antropología y, linalmente, política. Llama la atención el haber pasado diez años erigiendo su monumental obra: Crítica de la Razón Pura, que constituye la base de todo su pensamiento.

- La edición inglesa de Hans Reiss, Kant's Political Writings, nos ha ayudado a tener una visión total acerca del pensamiento político de Kant. Han sido importantes sus observaciones sobre los ensayos excluidos y los seleccionados, y su preocupación de no omitir aporles sustanciales, publicados en vida del autor. Queda, pues, a discreción de Reiss, la siguiente selección: Ideas para una historia universal en clave cosmopolita (1784); Una respuesta a la pregunta: ¿Qué es la Ilustracion? (1784); En torno al tópico: tal vez eso séa correcto en teoria, pero no sirve para la práctica (1793); La paz perpetua, un esbozo filosificico (1795); iragmentos de Metafísica de las costumbres (1797); El conflicto de las facultades (1797); y un fragmento de la Crítica de la Razion Pura (1781).

- Un estudio preliminar del pensamiento político de Kant nos ha dado aportes relevantes para la comprensión del mismo:

- Kant es poco conocido en filosofía política porque, primero, no hizo una obra grande y sistemática sobre política, y, segundo, por su estilo de no lácil lectura.

- Es una aherración pensar que Kant se preocupó de la rellexión política solamente en la última década de su vida, aunque sí es cierto que en ella la intensificio, en parte inspirado por los acontecimientos en torno a la Revolución Francesa. La nola más remota sobre reflexión política data de 1760) cuando estudiaba a Rousseau y el derecho natural.

- Hay cierla analogía entre la Revolución Francesa, la Independencia de los listados Unidos y el pensamiento político kantiano: la independencia del individuo frente a la autoridad y el problema de la libertad guarda coherencia con la reivindicación de ambas revoluciones de los derechos del ser humano. En algunos casos, como en Hacia la paz perpetua, Kant va mucho más lejos que los mismos planteamientos de ambas revoluciones. 
- I:n sus ideas polílicass. Kant se enlirenta a las leorias de Hobhes. Ioctere. Hume, Rousscalu y Macpuiavelo. También se enlirental a sus conlemporáneos. Hamann y Cedllicied, delendiendo el sino de la ilustración. Kant liene repercusiones posteriores en Schaller, von Ilumboldt. Fichle, Schelling. Hegel y Milrx.

- Nl leer los escritos polílicos de Kant, podemos constalar su rellexión de actualiclad, sobre lodo en nuestra aclual siluación de guerra y globalización. poniendo en tela de juicio la idea de progreso hacia mejor.

- Kant encuentra en la Nalluralesa la disposición de un progreso hacia mejor hasiado en la lental evolución de la razón, la cual se constalla no en el indivi(luo sino en la especie humana, a pesar de lantal estupicles y maldad, de retrocesos, de la megalomanía de los dloses de la licrat. ele. Podríamos decir cue la Nalluraleza es un tema transversal en lodass las rellexiones políticils halntianas.

- Sin embargo, Kant ve en la nalluralezal humana un claro anliggonismo gue lo calilica de 'insociable sociahilidad’. el cual es luente de guerra, pero lambién de superación constante y de plenilicación de los dotes humanos. I a 'ilustración es para Kant el último y mejor estadio de la plenilicación humana. cuando los hombres actúen racionalmente.

- Ante el problema de la libertad, y del antagonismo natural en los seres humanos. Kant sugiere la necesidad del derecho como entidad rectora y coerciliva de los excesos de liberlad de los seres humanos. I:I derecho vendría a prescribir una libertad regida por leyes. El derecho mejor sería el del régemen republiciano.

- Kant desaprucha los lueros de la revolución. porcue provoca tristes consecuencias y porque rompe con las hases de la regulación de los exeesos liberlinos. I al moral se convierte en correspondencial con lass leyes. No haly revolución, sino evolución a leyes cadla vey mejores. Para ello debe haber liberlade de los ciudarlanos y, sobre lodo, de los liblósolos que lienen el deber de señalar los crrores en la gestión de los mandalarios y proponerle caminos de solución. La libertad de pluma garantizaría esal evolución hacia leyes mejores. Kant es un posilivista jurílico, auncpue su libosolía élica permite y exige un andiamiaje axiológico para transtormar las leyes a mejor.

- Tras una luerte crílica a los excesos de Europa en los demás continentes. Kant augura los principios para una paz perpelua, sumamente revolucionarios incluso para nuestro liempo. Señala, además de la sujeción a un verdadero Estado de Derecho: la clesaparición lotal de los cejércilos: la relación horizontal entre países en una conlecleración de Estados y la no existencia de un gohierno munclial que permita una relación vertical entre unos países dominantes y otros dominados; instauración mundial de la paz mediante un 
diailogo ilustrado de las diferencias culturales y religiosas; y la consolidación de la par a lin de permitir el clesarrollo de las relaciones comerciales. Señala a su ver el papel clel lilósofó en su tarea de alumbrar la vida práctica de los hombres y las decisiones de los mandatarios.

Por ciltimo, el pensamiento kantiano, hasta (londe hemos visto, se apunta a la construcción de un reino donde los seres humanos, y la comunidad de ellos, sean lines en sí mismos; es una larea, por su puesto, de ilustración, pero lambién de libertad de pensamiento, de deseo de paz y sujeción a un (lerecho público (orden nacional) y a un derecho de gentes (orden internacional). Podemos concluir, junto con Rodríguez Aramayo, que Kant es un ulopista ucrónico, cuando diec: "Todo el pensamiento práctico de Kant es esencialmente revolucionario, en cuanto nos marca un horizonte utópico, unas melas príclicals cuya persecución irá remodelando el actual mundo fenoménico scguin el pallón cidélico aplicado".

\section{NoTAS}

1. I lamrzi (m) ciudad.com.ar) enviado a monografias.com hajo el lítulo Historia, edades de la pre/ristoria. "Edad moderna". encontrado en el sitio: whw.monografias.comstral)ajostoledpres.sheml.

2. Nuestra tesis açuí utilizanda no niega un concepto más amplio de modernidad como "híscfueda de cerlesas", caracterización yue acuña Luis González en su artículo El sino de la modernidad: la brisqueda interminable de certezas (publicado en la edición No 8.3 de esta revistil). En su antículo, el autor caracteriza culturalmente la modernidad desde cuatro vías: la de la razón. la de los sentidos, la de la moderación y la de la locura. Si hien es cierto que la modernidad no se reduce a la búsqueda de verdades por medio de la razón. lambién es cierto que sí hay un predominio de la misma, cuya madurez. se expresó en el movimiento de la llustración, al cual Kant se adhirió.

3. La hiogralía ha sido utilizada casi en su totalidad del recurso de filosofía en español: "ww.cihermous.com/cutores/kant, pero además se ha revisado y complementado desde: Jordi Cortés Morató y Antoni Martínez Riu. Diccionario de filosofía én (CD). R()M. Eelitorial Herder, Bareclona 1996.

4. Con este término nos referiremos a las tres principales obras de Kant: Crítica de la Razón Pura, Crítica de la Razón Práctica y Crítica del Juicio.

5. Ilans Reiss, Kant 's Political Writings, University Press, Cambridge 1971.

6. Ilans Reiss, Op. Cit. p. ix: "I have omitted other essays, ... which touch only marginally (in) politics."

7. Hhid., p. ix: "To print hoth works (se refiere a Metafisica de las costumbres y a $l: 1$ (omflicto de las facultades) in full would inevitably have distracted attention from the main purpose of this volume."

$x$. Id., p. $x$ : "In neither calse is anything of substance omitted. Kant is simply repeating points which he has made elsewhere".

9. Akademieausgabe signilica 'Edición académica', y se relierc a las Obras Completas de Immanuel Kant. Por su parte. Kant-Studien que signilica 'Estudios sobre Kant'. 
10. Ilinns Reiss. ()p. ('it., p. x: "These writings were published posthumously and Kant did not intend them to be published. They do not offer anything substintially diflerent trom what is found in his published writings. They are of len repetitive since many of lhem are rough notes, comments on the lexthook which he was using lor lectures on the theory of law and notes for lectures or (probahly) later publicaltions".

11. Alortunaldamente nosotros hemos leído las recientes tradecciones espanoblas, mucho mis digeribles que la versión original alemana o cue las mismas tratducciones de hace un cuilrto de siglo.

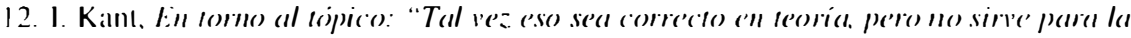
pricrica". Teconos. Maldrid 1986. p. 51.

13. I. Kant. Ideas peara una historia a'll clare cosmopolita. Teconos, Madrid 1987. p. 5.

14. Fisto yal dia pie a Fïchte y Schelling, primero, pero también a Hegel. para hacer de la

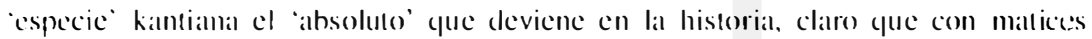
dilerentes. Aclemaís, el cue se leal a la Nalturaleral en mayúsculas, dia a suponer cue Kant la entiende como un sujelo con un plan oculto el cual lo desarrollaria en lia historia. Algo similar pasa con Ellacuría cuando dice que el sujelo de la historia es el phly/mm, es decir. la especie humana y no el individuo.

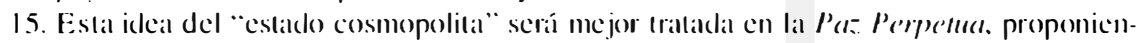
(lo en su lugar una Conlederación de Lstados Libres.

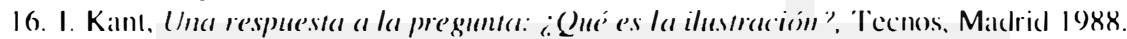

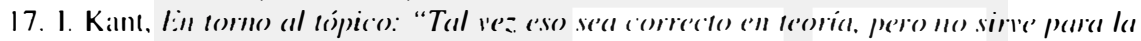
mactica". Teconos. Maldrid 1986, p. 56.

18. I. Kannt, Hacia la pas perpertua, Biblioteca Nueval, Maldrial 1999, p. 103.

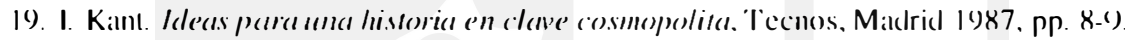

20. Ihicl., p. 8.

21. Ihicl. p. 17.

22. I. Kannt. Una respuessa a la presunta: a Que es la llustracioin" Teconos. Madrid 1988.

23. 1. Kant. Ide'as para una histerria a'n clate cosmopolita. Teconos, Madrid 1987, pp. 11.

24. I. Kant Critica de la Rarion Pura. Losalda, Buenos Aires 1960), p. 61

25. 1. Kant, Hacia la pas perpertua. Bihliotecia Nueva, Maldrid 1999, p. 81.

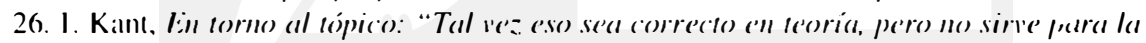
précicica", Tecnos, Madrid 1986, p. 6.

27. Ihid., p. 9.

28. Ihicl., p. 44.

29. Ibicl. p. 4 ().

30. íclem.

31. I.Kant, Lil conflicto de las facultades. Teconos, Madrid 1987, p. 81

32. Éste tópico será posteriormente reflexionado por la Segunda Internacional. de donde se conoce el clásico lexto de Rosa Luxemburg, Reforma y revolución.

33. I. Kant, Lin torno al tópico: "Tal vesesose sea correcto e'n teroria, pero no sirve para la prictica", Tecnos, Madrid 1986, p. 45-46.

34. Ih..p. 4(1)-47.

35. I. Kinnt, El conflicto de las facultades, Tecnos, Madrid 1987. p. 88.

36. Ih., p. 9() .

37. I. Kant, En torno al tópico: "Tal vez eso sea correcto en teoria, pero no sirver para la práctica". Teconos, Madrid 1986, p. 48.

38. I. Kant, Hacia la paz perpetua, Bihlioteca Nueva, Madrid 1999, p. 81. 
39) I:stos principios son descle ya utópicos y sumamente críticos con la realidad contemporáncia. Me pregunto cué dirían los organismos internacionales, las empresals transninionionales, los listados Unidos e Inglaterra, en su constante alán de intervenir en muestros países y ofrecernos recelas bancomundialistas para 'aminorar' la pobreza y adtherimos al gobierno mundial representado en el G-7.

4). Mrid.. p. I()( ).

4I. Ilicl., p. I(1)7.

42. Ilicl., p. I(1)7.

4.3. Ilide, p. II ().

44. I. Kant, lin torno al tópico: "Tal vez eso sea correcto en teoria, pero no sirve para la prictica". Teconos, Madrid 1986, p. 60).

45. I. Kamt (ritica de la Rarón Pura, Losada, Buenos Aires 1960), p. 62.

46. Roberto Rodrigues Aramayo, La "revolución asintónica" de la metafísica kantiana, (n: Estudio preliminar a I. Kant, Teoria y Práctica, Tecnos, Madrid 1986, pp. xxiiixxiv

47. Roberto Rodrigues Aramayo, El "utopismo ucrónico" de la reflexión kantiana sobre la historia. en Estudio preliminar a I. Kant. Ideas para una historia universal an 'lare cosmopolita !' otros escritos sobre filosofía de la Historia. Tecnos. Madrid 1987. pp. xxxviii-xxxix

\section{BIIBI.II)(iRNI.jA}

(iucresheim (ed). Immunuel Kant 1724-1974. Kamt comos pe'nuscudor politico. Inter Nationes, Bonn-Bad Goclesherg 1974

Kinll, Immanuel. Critica de la Razín Pura, Losada, Buenos Aires 1960, pp. 61-62.

ldeas para una historia universal en clave cosmopolita y otros escritos sobre

Filosofia de la Historia, Edición y cstudio preliminar de Roberto Rodríguez. Aramayo, Teconos, Madrid 1987.

Hacia la pas perpetua, un esbozo filosófico. Edición y estudio preliminar de Jacobo Muñor, Biblioleca Nueva, Madrid 1999.

Teoría y pracrica, Edición y estudio preliminar de Roherto Rodríguez Aramayo, Teconos. Madrid 1986.

Moralci. Jordi Cortés y Marlínez Rui, Antoni, Diccionario de fillosofía en CD-ROM. lEditorial Herder, Barcelona 1996.

Rciss, Ilans (ed). Kant', Political Writings. University Press, Cambridge 1971.

Sitios en Internet urilizades:

Laltanzzi. Mirla (mirtalatanzzi (a)ciudad.com.ar). La historia y las edades de la prehistoria. Irabajo enviado a monografias.com y que se encuentra en la siguiente dirección: n'ww.monografias.com/trabajos6/edpre.sheml.

Recursos de filosofía en español, que se encuentra en la siguiente dirección: ww'cibernouscomvautores/kant. 